\title{
THE EFFECTS OF TRACE FILLERS ON THE \\ RADIATION-INDUCED CROSSLINKING OF POLYETHYLENE*
}

This report ons pretice

This report whs prepined an account of wosk sponkered by the United Suter Govemment. Neither the Unise Sutes nor the Unites Shater Depatment of Erety; nor any of their employees, not any of their conltactors, wbentactors; or theti employees, makes any waminty, experas or inplied, of arumes any kpl linbility or responsibility for the accunary, completeness a uefuloess of any information, apparatus, product or procese discloned, or sepresents that its use would not infringe privtely owmed rights. by

\author{
Walter J. Chappas and Joseph Silverman \\ Laboratory for Radiation and Polymer Science \\ University of Maryland \\ College Park, Maryland 20742
}

\section{INTRODUCTION}

The effects of ionizing rediacion on the properties of polymer-filler systems have been observed for many years and, with one notable exception, are reasonably well understood. The exception is a Russian paper reporting an unusual phenomenon. This work by V. P. Gordiyenko et al. (1) describes the effect of low concentratioris of $\mathrm{SiO}_{2}$ and $\mathrm{TiO}_{2}$ fillers on the radiation induced crosslinking of poiyethylene. The principal results are summarized in Figure 1 taken from their work. It shows that the gel fraction of a low density polyethylene sheet irradiated with a dose of 5 megarads is increased by $60 \%$ by the addition of 0.2 volume percent of finely divided $\mathrm{SiO}_{2}(0.02 \mu \mathrm{m}$ particles) or 0.5 volume percent of coarse $\mathrm{TiO}_{2}(1 \mu \mathrm{m})$. Thus almost trace quantities of either additive can reduce substantially the dose required to achieve gel contents of industrial interest. The cost of radiation energy is expensive $(\sim \$ 1 / k W h)$. Thus if these results are readily reproducible, the cost of some industrial radiation processes, particularly the manufacturing of insulation and heat shrinkable packaging, could be cut significantly by the addition of small amounts of an inexpensive inert filier.

The experiments reported below are attempts to confirm and extend the results reported by Gordieynko et al.

\section{EXPERIMENTS}

Fumed silica from Sigma Corp. (0.007 $\mu \mathrm{m}$ diameter and $400 \mathrm{~m}^{2} \mathrm{~g}^{-1}$ surface area) ard Fisher Laboratory grade $\mathrm{SiO}_{2}$ gel $(75 \mu \mathrm{m}$ diameter) were used as fillers to produce a 
uniform polymer-filler blend with Microthene polyethylene powder (U. S. Industrial Chemical $\mathrm{Co.}_{\text {). }}$ The samples were blended at $140^{\circ} \mathrm{C}$ in a Brabender Plastograph (usually for $20 \mathrm{~min}$ ) and were then pressed for five minuter at $140^{\circ} \mathrm{C}$ and $470 \mathrm{~kg} \mathrm{~cm}^{-2}$, into $0.8 \mathrm{~mm}$ thick sheets on a Carver hydraulic press. The f was allowed to cool before the pressure was released and the sample removed. The cc intration and uniformity of the silica distribution in the filled samples were confirmed $t$ infrared analysis at $475 \mathrm{~cm}^{-1}$ (Figure 2), where there is a strong silica absorption peak and virtually no polyethylene absorption. The optical density at this wavelength was found to be proportional to the silica content, and the spectrum of each sample measured was independent of the position of the sheet under examination (Figure 3). An incidental finding is that the decadic molar extinction coefficient of the firie silica at $475 \mathrm{~cm}^{-1}$ is $70 \mathrm{M}^{-1} \mathrm{~cm}^{-1}$. The samples were cut into rectangular strips $(2 \times 10 \mathrm{~cm})$. Some were subjected to gamma radiation from the 25,000 curie cobalt 60 source at the University of Maryland at a dose rate of 2.2 Mrads $\mathrm{hr}^{-1}$; others were irradiated with a $2.2 \mathrm{MeV}$ electron beam from an RDI Dynamitron at Columbia Research Corp., Gaithersburg, Maryland at a dose rate of 5 Mrad $\sec ^{-1}$. Fricke dosimetry measurements were performed at Maryland for the Co-60 irradiations; electron beam dosimetry was performed by W. L. McLaughlin using radiochromic dye films. All recorded doses are estimated to be reliable within 5 percent. Also maximum-to-minimum doses in each sample did not exceed 1.07. Irradiations were done both in air and in a nitrogen atmosphere. The samples were annealed for $15 \mathrm{~min}$ at $110^{\circ} \mathrm{C}$ to minimize post-irradiation reactions. The gel fraction of the annealed strips was determined by Soxhlet extraction with boiling xylene in a nitrogen atmosphere for 70 hours followed by drying in a vacuum oven for another 50 hours at $55^{\circ} \mathrm{C}$. Measurements of the elastic modulus at $150^{\circ} \mathrm{C}$ were made using an Instron 1130 Universal Testing Machine.

The experimental conditions matched those of Gordiyenko et al. in most respects. The princlpal differences were as follows: (1) our use of 0.007 and $75 \mu \mathrm{m}$ silica instead of 
$0.02 \mu \mathrm{m} \mathrm{SiO}_{2}$; and (2) our post-irradiation conditioning procedure consisted of annealing the samples for 15 minutes at $110^{\circ} \mathrm{C}$ rather than 1.5 minutes at $130^{\circ} \mathrm{C}$. We also included gamma irradiations in addition to the electron beam irradiations, and measurements of the oxygen effect and tensile properties, but did not repeat the Gordiyenko measurements of allyl radical concentration by ESR, and of crystallinity by $x$-ray diffraction.

\section{RESULTS AND DISCUSSION}

Prior to our experiments, we considered several possible explanations of the published results. In general, our speculations focused on possible interactions at the interface between the filler and the polymer during the irradiation. One possibility is the higher dose rate in the polymer near the interface with the filler. This would arise from the following considerations. The energy absorbed per gram in the bulk polymer and the bulk silica should be the same but the flux density of scattered electrons should vary directly as the density (neglecting differences due to atomic number). Thus at the interface, the electron fiux into the polymer would be perhaps twice that entering the filler. Another mechanism that could lead to an enhanced effect at the interface, involves the transfer of electron energy absorbed by the filler to the surface; this effect has been reported (2) for several systems involving a substance absorbed on silica gel. A third factor that may be involved is some specific chemical interaction that may occur at the interface under the influence of ionizing radiation; this interaction may be enhanced by the increased dose effects suggested above. Even collectively, however,these possibilities do not provide a reasonable basis for explaining the sharp increase in crosslinking caused by the addition of only 0.2 volume percent of the oxide. The volume fraction of the polyethylene at the interface in the 25-50 $\AA$ region that would be involved is too small.

At first we blended all samples with the coarse filler $\left(75 \mu \mathrm{m} \mathrm{SiO}{ }_{2}\right.$ ) for $15 \mathrm{~min}$ at $150^{\circ} \mathrm{C}$ in the Brabender Plastograph. We found that higher filler content led to greater 
discoloration. We decided to reduce the blending time as filler content was increased to produce composites that were colorless to slight yellow. The gel versus filler concentration data (Figure 4) show no evidence of the reported maximum.

Clearly the discoloration of the polymer was due to the abrasive action of the filler. This abrasive action may be viewed in two different ways. Although the temperature of the blender was controlled as to keep the average temperature of the melt constant, there is a possibility of local microscopic heating. There have been studies of thermal degradation (5) which arises primarily from breakage of the $\mathrm{C}-\mathrm{H}$ bonds and the subsequent oxidation of the secondary alkyl radical. The known chemistry associated with this process leads to main chain unsaturation at the expense of the pendant vinyl groups, with no net increase in the total concentration of unsaturated species. Another mechanism for the abrasive action could be purely mechano-chemical in nature. For this type of degradation the chains are torn into primary alkyl radicals by the action of the blender. The free radicals produced from the mechanical fracture of polyethylene at $77^{\circ} \mathrm{K}$ has been studied by Sohma et al. (6). They suggest that subsequent radical recombination would increase terminal vinyl unsaturation which might be expected to enhance the radiation effect to some extent. Thus even though the initial experiments with coarse silica did not show an increase in the gel content with increasing filler content, finely divided silica could enhance thermal and mechano-chemical effects.

Blending experiments were performed using the $0.007 \mu \mathrm{m} \mathrm{SiO} 2^{*}$ Infrared analysis shows little change in the concentration of the unsaturated species, but a significant increase in the carbonyl absorption band at $1700 \mathrm{~cm}^{-1}$ (Figure 5). Blending experiments disclese that filler content, particle size, blending speeds, and blending times all affect the degree of discoloration and oxidation (Figure 6). Analysis of our samples shows that the principal unsaturation is in the form of pendant vinyl groups, which build up to a constant level in less than 15 minutes. Terminal unsaturation builds up more slowly; even 
after 1 hour, it is less than $20 \%$ of the pendant vinyl unsaturation. Main chain unsaturation after 15 minutes of blending time is also less than $20 \%$ of the pendant vinyl unsaturation; after 60 minutes of blending it is smaller than but comparable to that of the pendant vinyl unsaturation. Fifteen minutes in the blender produces carbonyl groups with a yield comparable to that of the unsaturation; after 60 minutes, the carbonyl groups dwarf the unsaturated groups. These data suggest a combination of reactions whose chief consequences are negligible for purposes of this paper. The production of vinyl groups in the composites by the action of the blender is just too small to have an impact on the subsequent radiation chemistry.

The radiation crosslinking experiments with polyethylene samples containing $0.007 \mu \mathrm{m}$ silica were performed both in air and an inert atmosphere and with high energy electrons (Figure 7) as well as gammas (Figure 8). Blending time for this series and all the experiments that followed was 20 min. The results shown in Figure 8 reflects the role oxygen plays as a scavenger molecule in the presence of alkyl radicals, and indicates the significance of oxygen diffusion as a rate controlling parameter in the crosslinking reactions; however, the results do not show the enhanced glel yields observed in the work of Gordiyenko et al.

The elastic modulus measurements were made above the crystalline melting temperature to determine whether any unusual viscoelastic behavior could be observed in the filled samples. Figure 9 shows that the modulus measurements of gamma irradiated samples filled with $0.007 \mu \mathrm{m} \mathrm{SiO}_{2}$ compare closely with the moduli calculated from the Guth-Gold equation: $M=M_{0}\left(1+2.5 v_{f}+14.1 v_{f}^{2}\right)$ where $M_{0}$ is the modulus of unfilled sample, and $v$ is the volume fraction of the filler. (Each experimental point is the mean of four measurements). Thus trace fillers do not have any unusual effects on mechanical behavior. 
The details of the work by Gordiyenko et al. as outlined in the experimental section of their paper are incomplete. Parameters such as blending time, temperature, and speeds were not reported. On the other hand, all our results show that substantial changes in these experimental conditions do not affect the gel content. Nevertheless we cannot exclude the possibility that a precise replica of their equipment, materials, and conditions could yield their results. Alsa it may be useful to examine the mechano-chemistry during the blending operation to search for conditions that produce pendant vinyl groups which lead to a chain reaction of radiation-induced crosslinking (7).

There are publications reporting improved mechanical properties of filled polyethylene after irradiation (3,4). They describe room temperature, physical and mechanical measurements, primarily creep and tensile strength. However the samples typically contain 15 percent filler before significant effects are observed. There is nothing in these works that would lead one to expect the effects reported by Gordiyenko et al.

The authors are grateful to Columbia Research Corp. (Gaithersburg, Maryland) for the use of their RDI Dynamitron and for the assistance of Renu Garg and Jeffrey Porter in the performance of the experiments. This work is sponsored by the Division of Chemical Sciences of the U. S. Department of Energy.

\section{$\underline{\text { References }}$}

1. V. P. Gordiyenko, N. T. Kartel, K. A. Suprunenko, V. N. Doroshenko and A. M. Kabakchi, "Investigation of Radiation Crosslinking of Polyethylene in Heterogeneous Systems", Vysokomolekulyarnyye Soyedineniya, 17, 8, 1737 (1975) Moscow.

2. J. M. Caffrey, Jr. and A. O. Allen, J. Phys. Chem., 62, 33 (1958). 
3. R. A. V. Raff, "The Grafting of Organic Polymers onto Inorganic Substances", U. S. Atomic Energy Comm., Final Report RLO-2043-2, January 30, 1968.

4. A. F. Gilbert and F. M. Precopio, U. S. Patent 3,804,114 (1963).

5. D. L. Wood and J. P. Luongo, Modern Plastics, p. 132, March, 1961.

6. J. Sohma, T. Kawashima, S. Shimada, H. Kashiwabara and M. Sakaguchi, "ESR Applications to Polymer Research", (P. O. Kinell, B. Rånby and V. Runnström-Reio, eds.) p. 225, Wiley, New York (1973).

7. A. von Raven, and H. Heusinger, J. Poly. Sci., 12, 2255 (1974). 

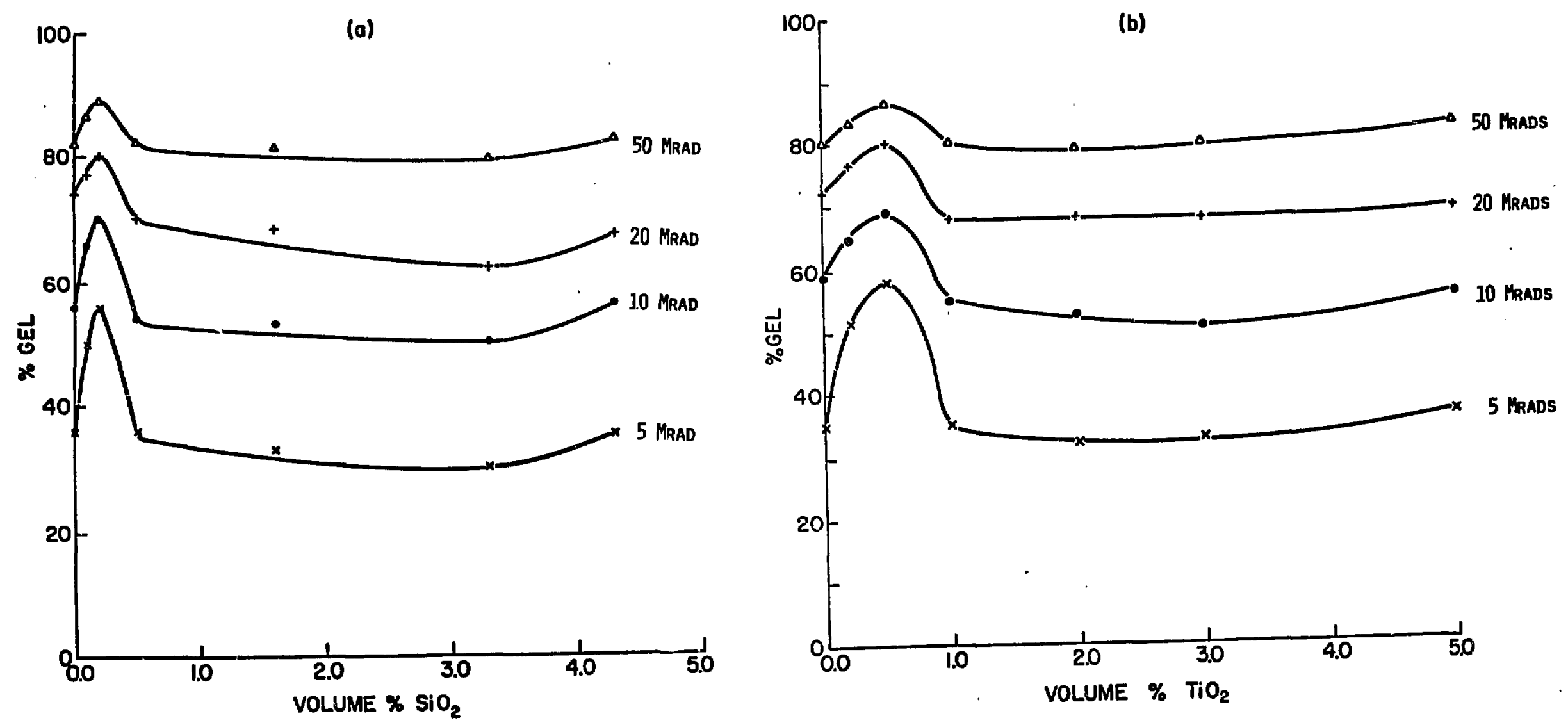

Figure 1. Effects of $\mathrm{SiO}_{2}$ and $\mathrm{TIO}_{2}$ ON the radiation induced CRosslinking of polyethyLene as described by Gordiyenko et al. 
A)

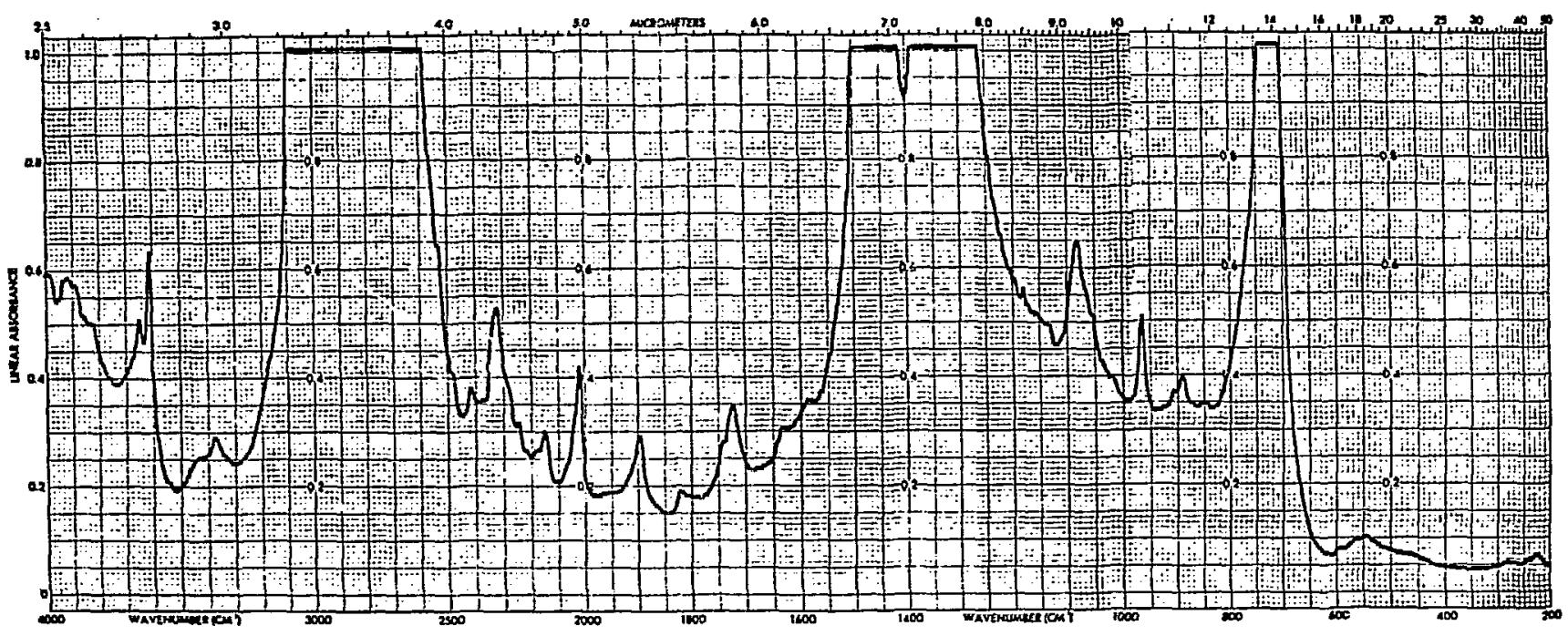

B)

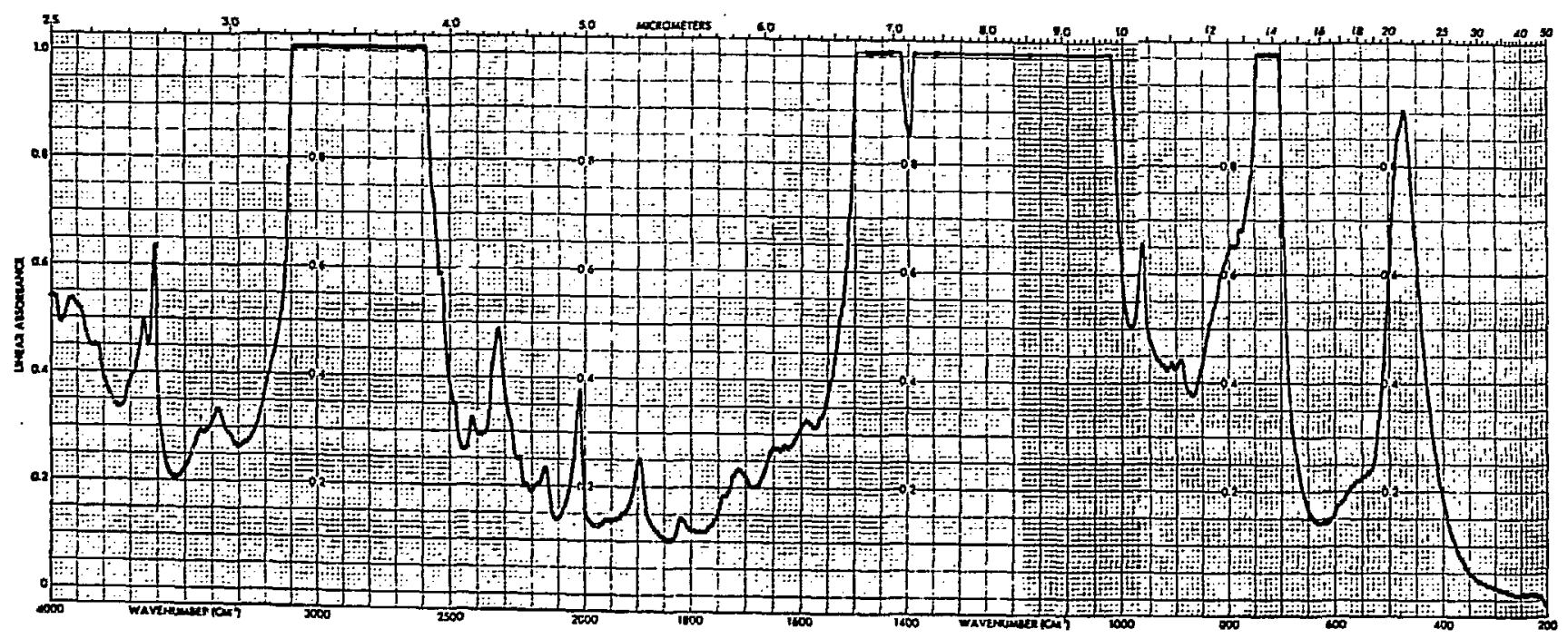

Figure 2. INFRAREd SPECTRA OF A) PURE POLYETHYLENE AND B) POLYETHYLENE FILLED WITH $0.007 \mu M$ SILICA $(0.5$ VOLUME PERCENT), 


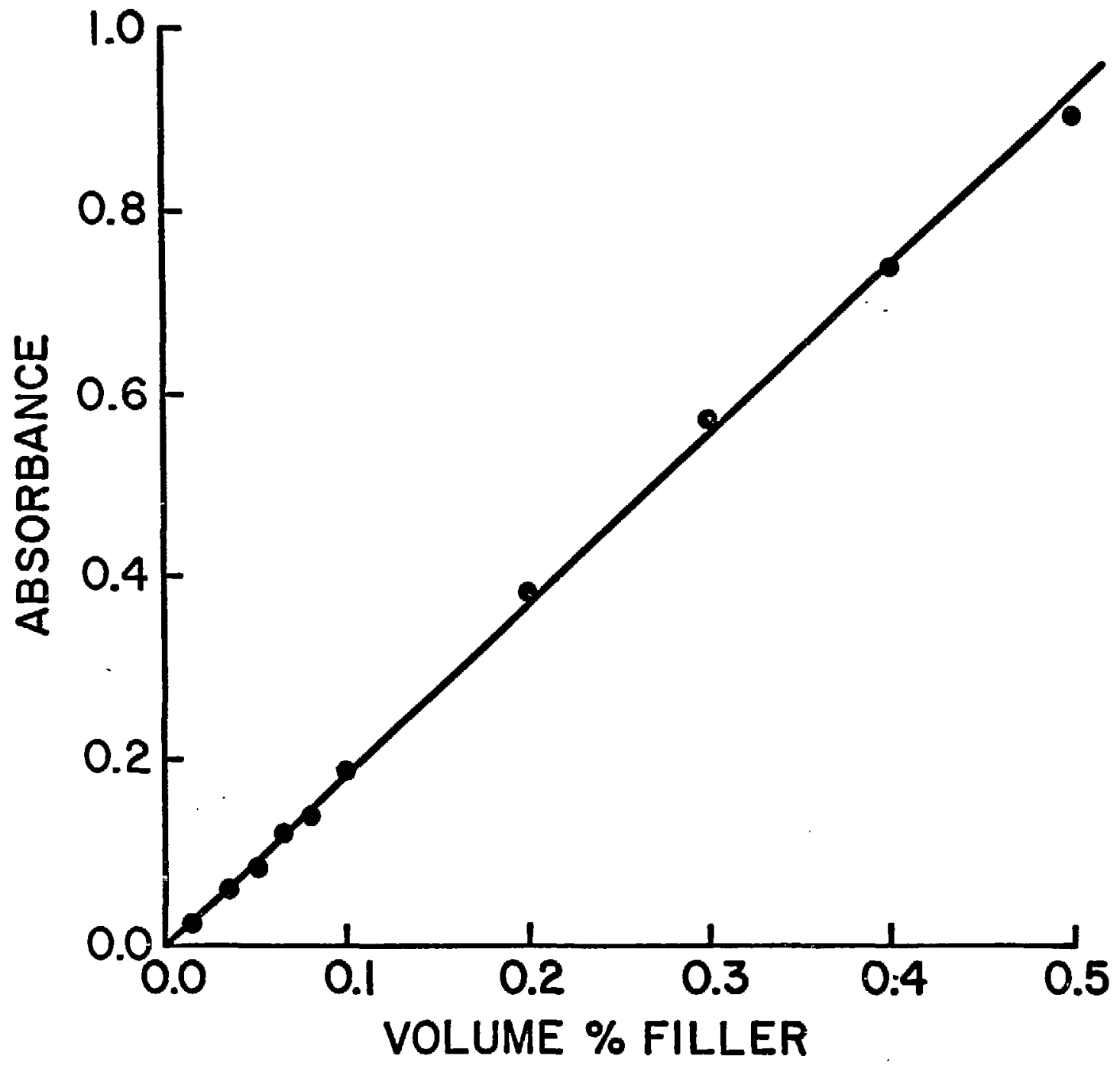

Figure 3. THE CONCENTRATION AND UNIFORMITY OF THE SILICA IN THE FILLED SAMPLES AS CONFIRMED BY INFRARED ANALYSIS AT $475 \mathrm{~cm}^{-1}$. 


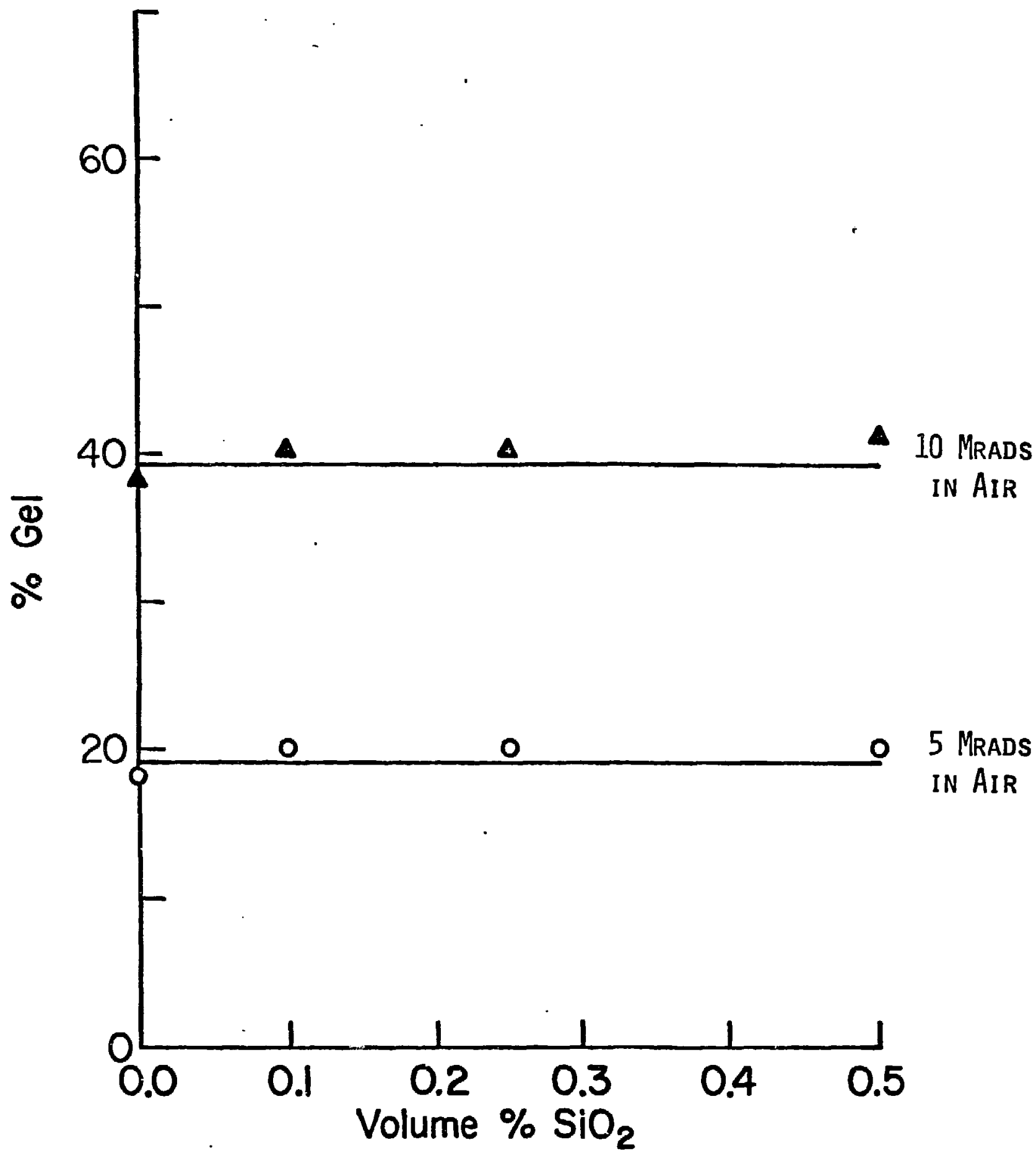

Figure 4. Percent gel as a function of concentration OF $75 \mu \mathrm{M} \mathrm{S} 0_{2}$. 


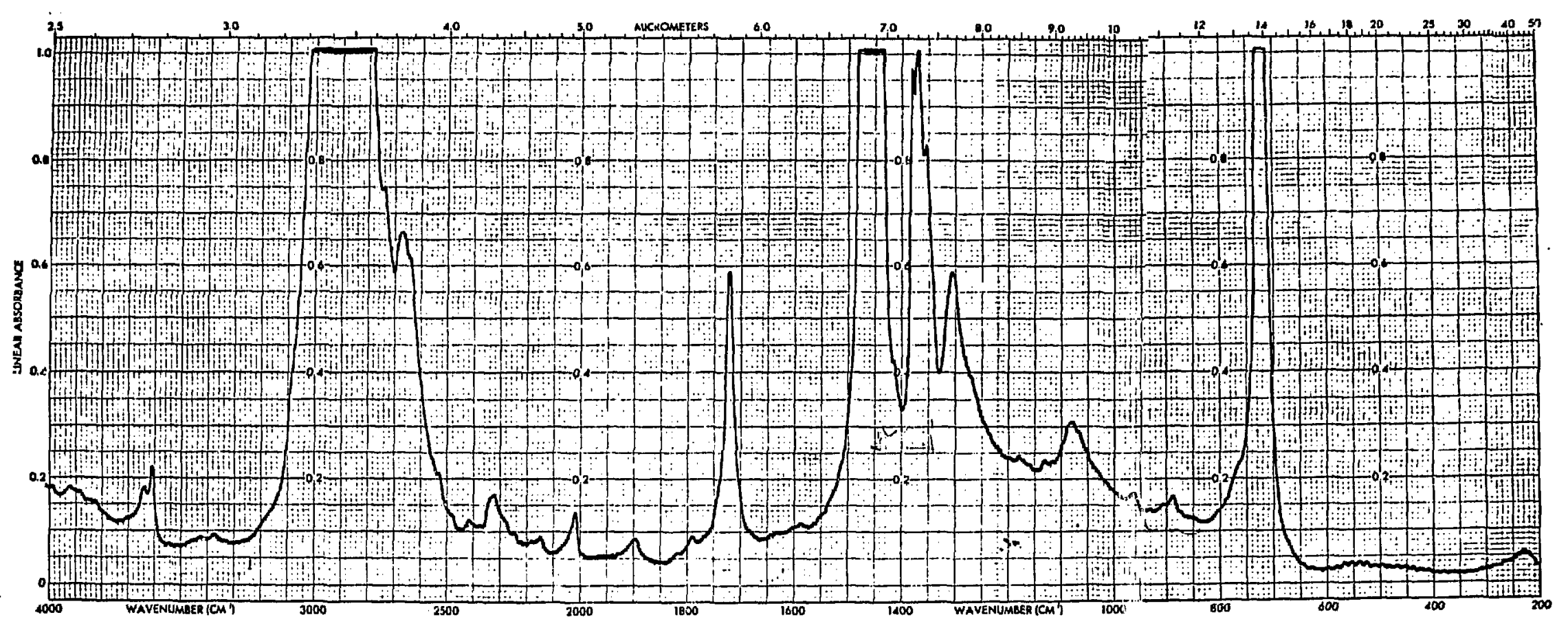

Figure 5. Polyethylene blended for 60 Min at 120 RPri and $150^{\circ} \mathrm{C}$ 


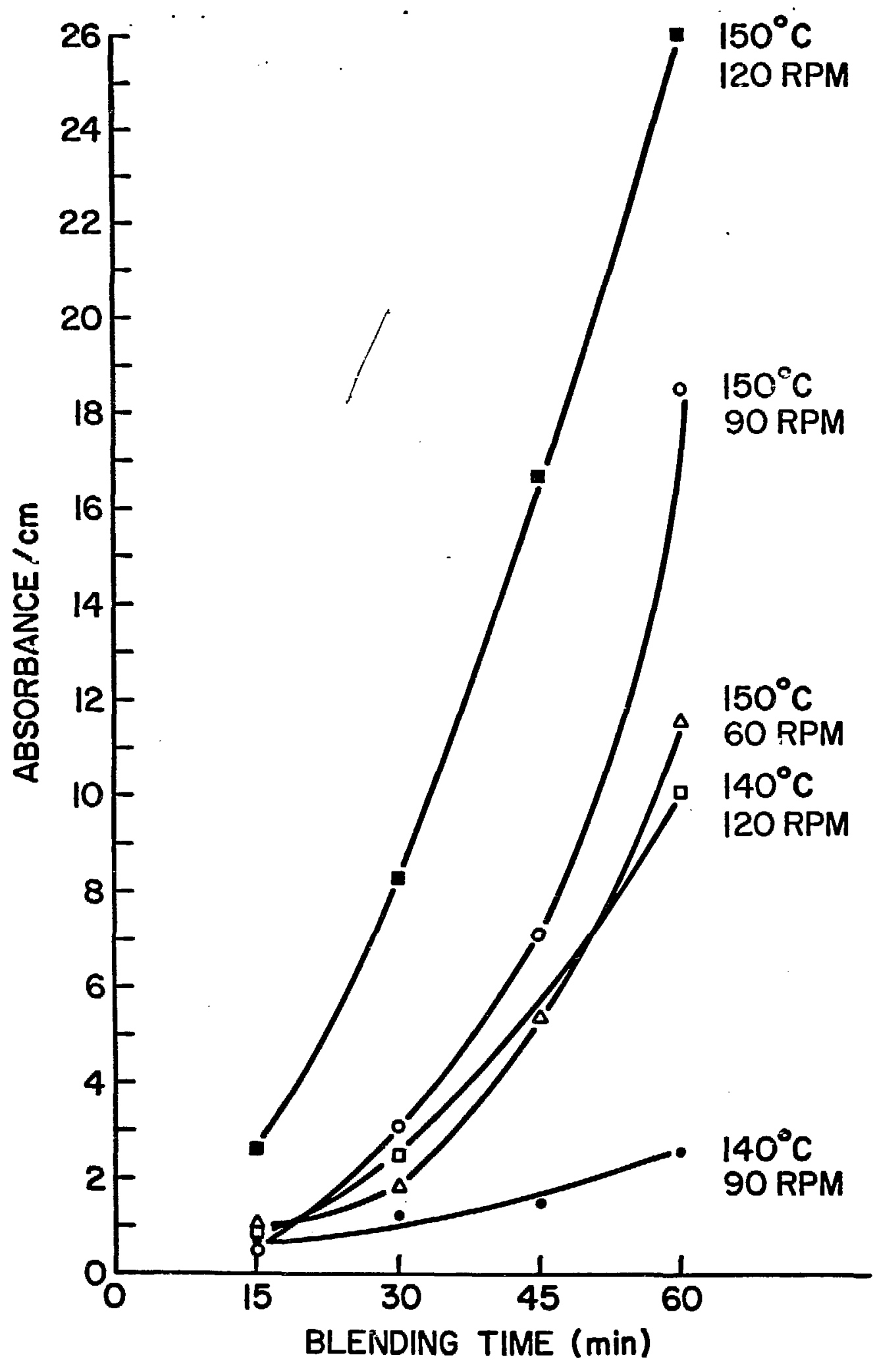

Figure 6. Carbonyl concentration as a function of BLENDING TIME BY IR ABSORPTION AT $475 \mathrm{~cm}^{-1}$. 


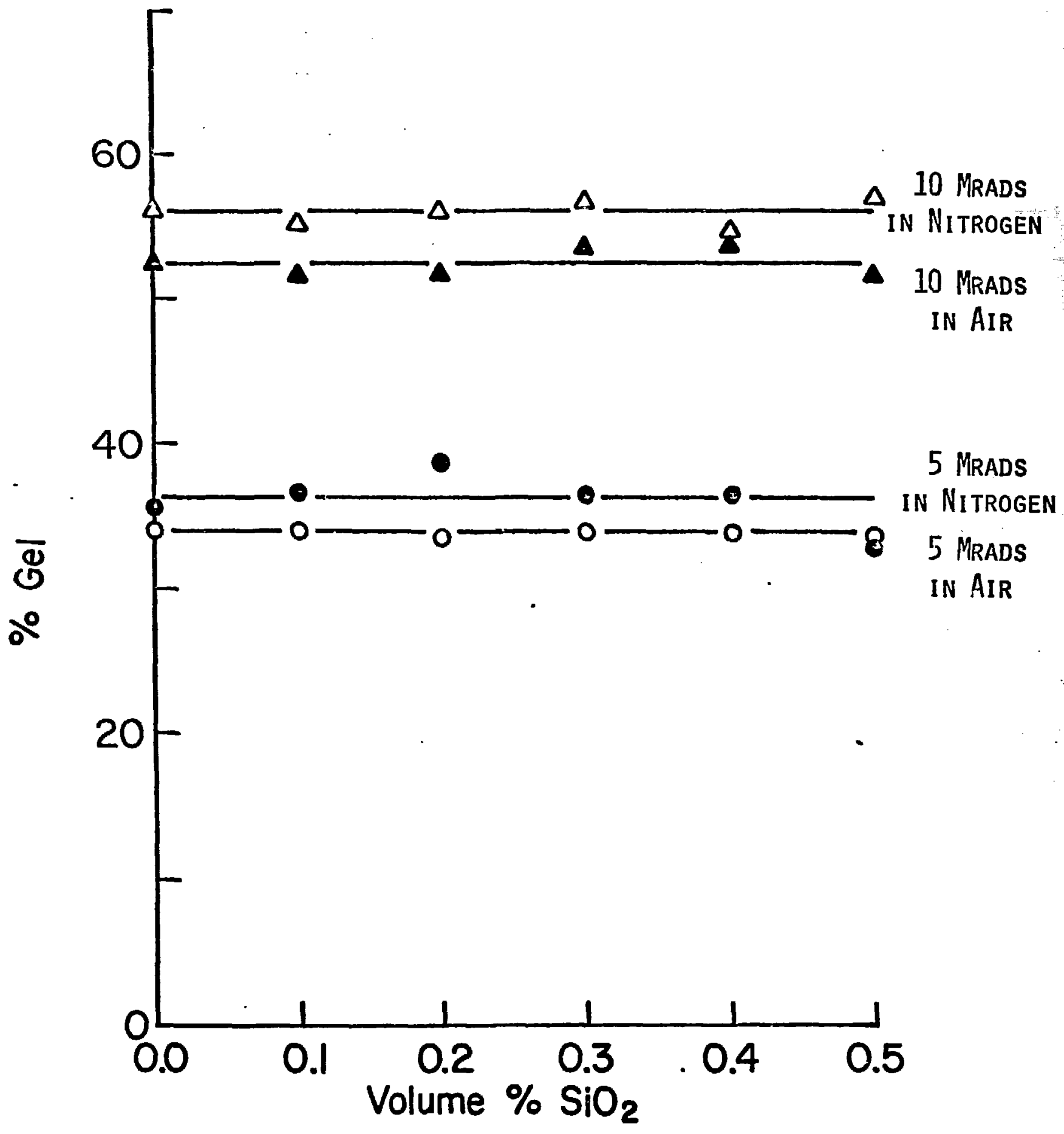

Figure 7. The efFects OF FILLERS ON THE GEL PRODUCTION in PE IRRADIATEd by ELECTRONS IN THE PRESENCE AND ABSENCE OF OXYGEN. 


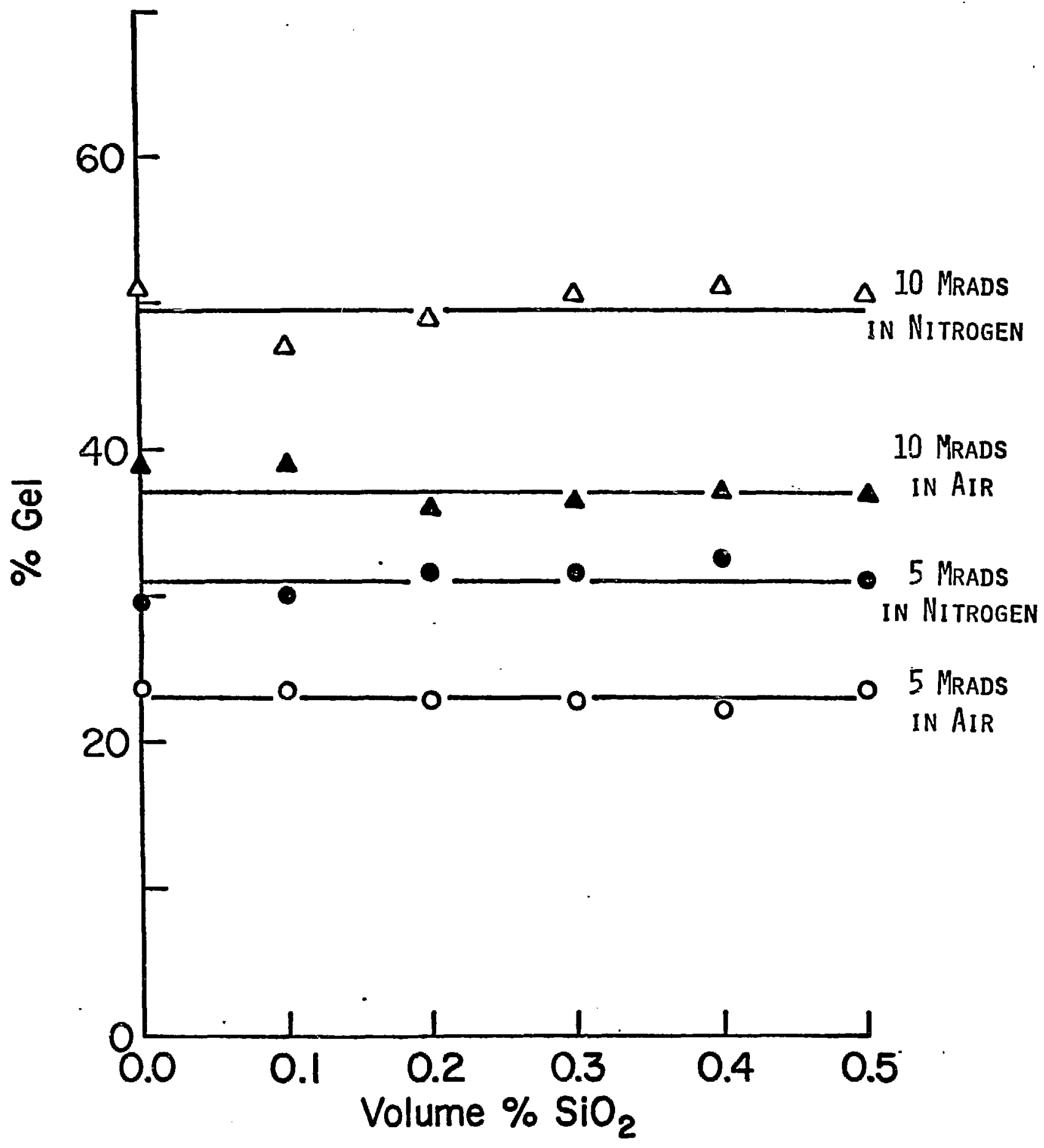

FigURE 8. THE EFFECTS OF FILLERS ON THE GEL PRODUCTION In PE IRradiated bY gammas in the PRESENCE AND ABSENCE OF OXYGEN. 


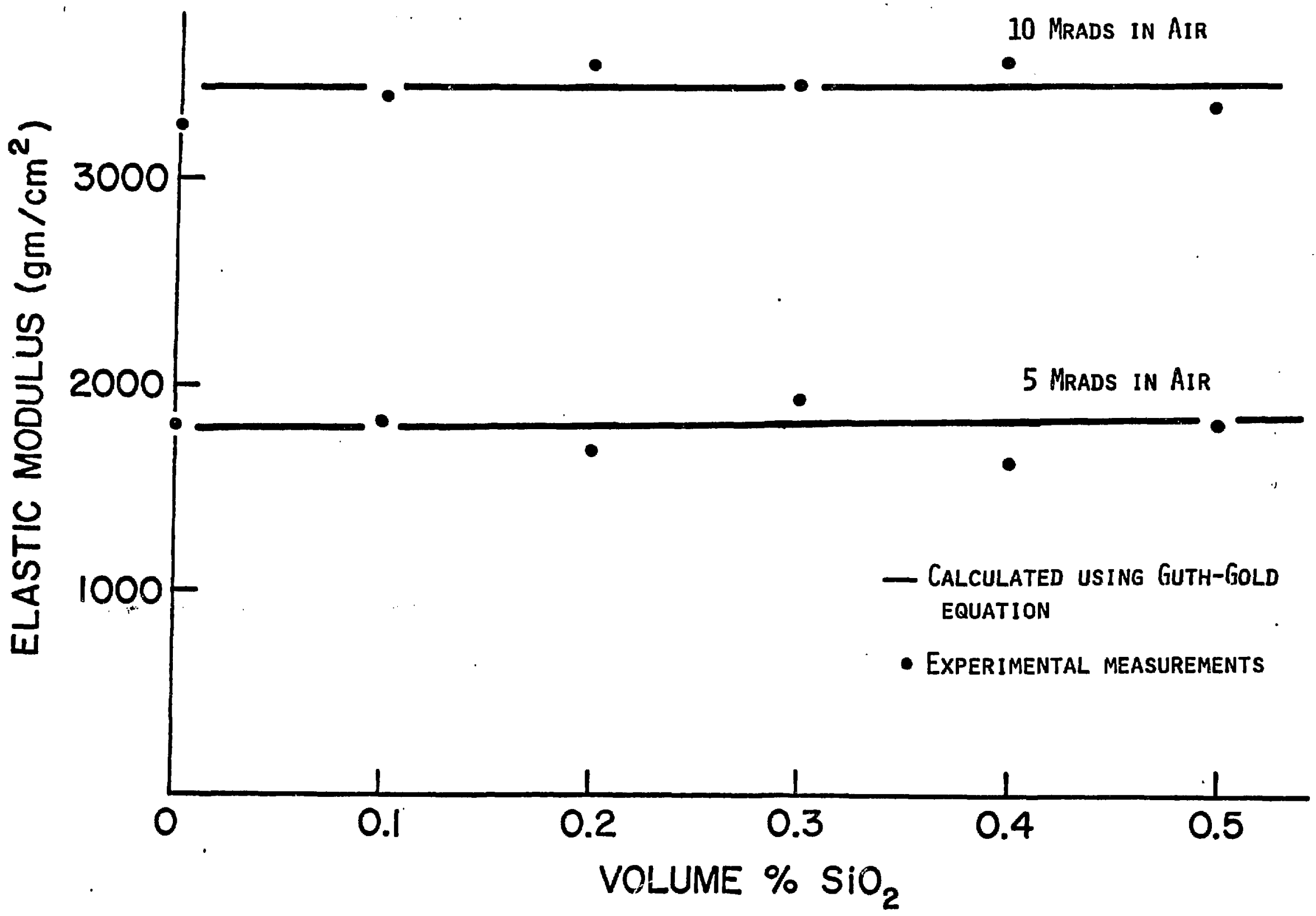

Figure 9. The effect of fillers on the elastic modulus of PE irRadiated by GAMMAS IN THE PRESENCE OF OXYGEN, 